\title{
Asymptotic Methods in Optimization of Inventory Business Processes
}

\author{
Lidiia Horoshkova* \\ Department of business, management \\ organizations and logistics \\ Zaporizhzhia National University \\ Zaporizhzhia, Ukraine \\ http://orcid.org/0000-0002-7142-4308
}

\author{
Ievgen Khlobystov \\ Department of ecology \\ National University of «Kyiv-Mohyla \\ academy» \\ Kyiv, Ukraine \\ University of Economics and \\ Humanities \\ Bielsko-Biala, Poland \\ http://orcid.org/0000-0002-9983-9062 \\ Svitlana Markova \\ Department of Business Administration \\ and Management of Foreign Economic \\ Activity \\ Zaporizhzhia National University \\ Zaporizhzhia, Ukraine \\ https://orcid.org/0000-0003-0675-0235
}

\author{
Volodymyr Volkov \\ Department of business, management \\ organizations and logistics \\ Zaporizhzhia National University \\ Zaporizhzhia, Ukraine \\ http://orcid.org/0000-0002-1270-895X
}

\author{
Department of Business Administration \\ and Management of Foreign Economic \\ Activity \\ Zaporizhzhia National University \\ Zaporizhzhia, Ukraine \\ http://orcid.org/0000-0002-9410-3830
}

\section{ANALYSIS OF RECENT STUDIES AND PUBLICATIONS THAT HAVE INITIATED PROBLEM SOLUTION, WHICH THE AUTHOR REFERS ON}

R.R. Larina, O.Yu. Lukianova [1], G.V. Mel`nyk, V.I. Skitska [2], A.O. Kolomitseva, V.S. Yakovenko [3] and other scholars dedicated their research to the issue of logistics` business processes` modeling at an enterprise. S.V. Ocheretenko [4], P. Tripaty, S. Shukla [5] built inventory`s mathematical models; N.O. Markova, I.A. Kiosseva [6], O.V. Posilkina, Yu.E. Novitskoy, Yu.M. Penkin, O.Yu. Gorbunov [7], R. Iassa, S. Ikatrinasari [8] and other researchers studied peculiarities of multi-nomenclature systems of inventory. S. Jaggi, S. Goel, and M. Mittal [9] proposed the specifics of inventory management system taking into account deficit for retail trade with allowable late payment. In the context of uncertainty caused, for example, by inflation, unexpected ups and downs in the economy, scientists like A. Einan and D. Kropp [10], S. Wang [11], A. Yousefli and M. Gazanfari [12] built appropriate inventory models that take these indicators into account. The proposed optimization methods solve some of the inventory management problems; however, real management often requires building of analytical models that provide solutions in the form of easy-to-use formulas.

\section{ARTICLE OBJECTIVES}

Objective of the study is to develop a multinomenclature model of inventory business processes using asymptotic methods and to obtain easy-to-use analytical formulas to determine model parameters when ordering and inventory holding costs meet insufficient cyclical changes.

\section{THE MAIN MATERIAL OF THE RESEARCH WITH JUSTIFICATION OF FINDINGS}

Application of inventory models enables company management to reduce fixed and variable production costs, ordering and sales. All costs associated with a multinomenclature ordering of resources or goods from a supplier can be represented by two components: 


$$
C=C_{0}+\sum_{i=1}^{k} C_{i}=\sum_{i=0}^{k} C_{i}
$$

$C_{o}$ - costs incurred during transportation,

$C_{i}-$ costs that depend on the amount of transactions performed when forming a specific order. Therefore, the costs of ordering $k$ of product lines from one supplier can be represented as (1).

If to specify total commodity consumption as $i$ during a certain period as $S_{i}$, unit storage costs as $C x_{i}$, cycle of supply as $T$, period as $D$, and if synchronistic supply $k$ of product lines take place, then total costs are (2) [13].

$$
C_{\Sigma}=\frac{D}{T} \sum_{i=0}^{k} C_{i}+\frac{T}{2 D} \sum_{i=1}^{k} S_{i} C x_{i} \rightarrow \min .
$$

If model parameters are fixed (2), the optimal value of multi- nomenclature supply cycle $T_{\text {opt }}$ is defined as follows [13]:

$$
T_{\text {opt }}=D \sqrt{\frac{2 \sum_{i=0}^{k} C_{i}}{\sum_{i=1}^{k} S_{i} C_{x i}}}
$$

Assumption about the model's fixed parameters reduces possibility and effectiveness of its practical application. Let us apply asymptotic methods that allow, without violating this assumption, to perturb the model parameters. One of these parameters is ordering costs, which are fixed in the inventory optimization model. In practice, this parameter may increase cyclically due to inflationary processes, consumer and producer expectations, the ratchet effect, etc. Let us assume that during a fixed period ordering costs, namely their transport component, rise manyfold by $1 \%$. Then in $n$ periods it is $C_{0} \cdot\left(1+\frac{l \%}{100 \%}\right)^{n}$. Specifying addends` perturbation as a small parameter $\frac{l \%}{100 \%}$, this correlation can be presented as: $C_{0} \cdot(1+\varepsilon)^{n}$, when $\varepsilon<<1$.

In practice, ordering costs and inventory holding costs increase as a result of higher electricity and utilities prices. Assume that holding cost increases with each period by $j \%$. Analogously, considering value $\beta=\frac{j \%}{100 \%}(\beta<<1)$ as a small parameter, we obtain correlation of inventory holding costs as $C_{x i}(1+\beta)^{m}$.

To increase the proposed model's efficiency in manufacturing enterprises activity, it is advisable to take into account different combinations of parameter values $n$ i $m, \varepsilon$ i $\beta$. Multiplicity $m$, which characterizes frequency of change in inventory holding costs is relatively less than the multiplicity $n$, which characterizes changes in order fulfillment. These terms can be taken into consideration in the model, for example when $m=[\mathrm{n} / 2], m=[\mathrm{n} / 3]$ etc., where [ ] - a quotient.

Let $T^{*}$ opt be an asymptotic decomposition by two small parameters $\varepsilon$ i $\beta$ :

$$
T^{*}{ }_{o p t}=T_{0}+T_{1} \varepsilon+T_{2} \beta+T_{3} \varepsilon^{2}+T_{4} \varepsilon \beta+T_{5} \beta^{2}+\ldots
$$

where $\varepsilon$ i $\beta$-parameters of perturbation.

Let us substitute perturbed values of the transport component of order fulfillment costs and storing inventory costs, as well as decomposition $T_{o p t}^{*}$ by degrees of small parameters $\varepsilon$ and $\beta$ to formula (3), not taking into account terms of order $\varepsilon^{3}, \beta^{3}, \varepsilon^{2} \beta$, $\varepsilon \beta^{2}$ and higher:

$$
\begin{gathered}
\left(T_{0}+T_{1} \varepsilon+T_{2} \beta+T_{3} \varepsilon^{2}+T_{4} \varepsilon \beta+T_{5} \beta^{2}\right)^{2}= \\
D^{2} \frac{\left(2 C_{0}(1+\varepsilon)^{n}+2 \sum_{i=1}^{k} C_{i}\right)}{(1+\beta)^{m} \sum_{i=1}^{k} S_{i} C_{x i}} .
\end{gathered}
$$

Decomposition of function $(1+\varepsilon)^{n} \mathrm{i}(1+\beta)^{-m}$ to Taylor's series expansion and neglecting members of higher orders, after raising square of both equality parts (5), we obtain:

$$
\begin{gathered}
T_{\mathrm{O}}^{2}+2 \boldsymbol{T}_{\mathrm{0}} \boldsymbol{T}_{1} \varepsilon+2 T_{\mathrm{o}} \boldsymbol{T}_{2} \beta+\left(\boldsymbol{T}_{1}^{2}+2 \boldsymbol{T}_{\mathrm{o}} \boldsymbol{T}_{3}\right) \varepsilon^{2}+ \\
+\left(2 \boldsymbol{T}_{\mathrm{0}} \boldsymbol{T}_{4}+2 \boldsymbol{T}_{1} \boldsymbol{T}_{2}\right) \varepsilon \beta+\left(\boldsymbol{T}_{2}{ }^{2}+2 \boldsymbol{T}_{\mathrm{o}} \boldsymbol{T}_{5}\right) \beta^{2}= \\
=D^{2} \frac{\left(2 C_{0}\left(1+n \varepsilon+\frac{n(n-1)}{2} \varepsilon^{2}\right)+2 \sum_{i=1}^{k} C_{i}\right) \cdot\left(1-m \beta+\frac{m(m+1)}{2} \beta^{2}\right)}{\sum_{i=1}^{k} S_{i} C_{x i}}
\end{gathered}
$$

Equating coefficients with similar parameters` degrees $\varepsilon$ and $\beta$, we obtain system of six equations to identify unknowns $T_{i}(i=0, \ldots, 5)$ :

$$
\begin{gathered}
\varepsilon^{\mathrm{o}}: T_{\mathrm{O}}^{2}=\frac{D^{2}}{\sum_{i=1}^{k} S_{i} C_{x i}}\left(2 C_{0}+2 \sum_{i=1}^{k} C_{i}\right)=D^{2} \frac{2 \sum_{i=0}^{k} C_{i}}{\sum_{i=1}^{k} S_{i} C_{x i}} \\
\varepsilon^{1}: T_{\mathrm{O}} T_{1}=D^{2} \frac{2 C_{0} n}{\sum_{i=1}^{k} S_{i} C_{x i}}
\end{gathered}
$$

Solving equations (7)-(12), we obtain:

$$
T_{\mathrm{O}}=D \sqrt{\frac{2 \sum_{i=\mathrm{O}}^{k} C_{i}}{\sum_{i=1}^{k} S_{i} C_{x_{i}}}} \quad T_{1}=D \sqrt{\frac{2 \sum_{i=0}^{k} C_{i}}{\sum_{i=1}^{k} S_{i} C_{x_{i}}}} \cdot \frac{C_{\mathrm{O}} n}{2 \sum_{i=\mathrm{O}}^{k} C_{i}},
$$




$$
\begin{gathered}
T_{2}=D \sqrt{\frac{2 \sum_{i=0}^{k} C_{i}}{\sum_{i=1}^{k} S_{i} C_{x_{i}}} \cdot\left(\frac{-m}{2}\right)}, \\
T_{3}=D \sqrt{\frac{2 \sum_{i=0}^{k} C_{i}}{\sum_{i=1}^{k} S_{i} C_{x_{i}}}} \cdot\left(\frac{C_{0} n(n-1)}{4 \sum_{i=0}^{k} C_{i}}-\frac{C_{0}^{2} n^{2}}{8\left(\sum_{i=0}^{k} C_{i}\right)^{2}}\right), \\
T_{4}=D \sqrt{\frac{2 \sum_{i=0}^{k} C_{i}}{\sum_{i=1}^{k} S_{i} C_{x_{i}}}} \cdot \frac{C_{0}(-m n)}{4 \sum_{i=0}^{k} C_{i}} \\
T_{5}=D \sqrt{\frac{2 \sum_{i=0}^{k} C_{i}}{\sum_{i=1}^{k} S_{i} C_{x_{i}}}} \cdot \frac{m(m+2)}{8}
\end{gathered}
$$

Asymptotic representation of the optimum value of multi- nomenclature supply cycle $T_{o p t}^{*}$ will be presented as (14) or (15):

$$
\begin{gathered}
T_{o p t}^{*}=D \sqrt{\frac{2 \sum_{i=0}^{k} C_{i}}{\sum_{i=1}^{k} S_{i} C_{x_{i}}}} \cdot\left(1+\frac{C_{0} n}{2 \sum_{i=0}^{k} C_{i}} \varepsilon-\frac{m}{2} \beta+\left(\frac{C_{0} n(n-1)}{4 \sum_{i=0}^{k} C_{i}}-\frac{C_{0}^{2} n^{2}}{8\left(\sum_{i=0}^{k} C_{i}\right)^{2}}\right) \cdot \varepsilon^{2}-\right. \\
\left.-\frac{C_{0} n m}{2 \sum_{i=0}^{k} C_{i}} \varepsilon \beta+\frac{m(m+2)}{8} \beta^{2}\right), \\
T_{o p t}^{*}=T_{o p t r}\left(1+\frac{C_{0} n}{2 \sum_{i=0}^{k} C_{i}} \varepsilon-\frac{m}{2} \beta+\left(\frac{C_{0} n(n-1)}{4 \sum_{i=0}^{k} C_{i}}-\frac{C_{0}^{2} n^{2}}{8\left(\sum_{i=0} C_{i}\right)^{2}}\right) \cdot \varepsilon^{2}-\frac{C_{0} n m}{4 \sum_{i=0}^{k} C_{i}} \varepsilon \beta+\frac{m(m+2)}{8} \beta^{2}\right)
\end{gathered}
$$

One can see, that when $\varepsilon=0$ and $\beta=0$ we obtain marginal transformation to "not perturbed" solution of this kind (3).Let us test the built multi-nomenclature model of optimization of inventory business processes under «perturbed» parameters on the example of the enterprise

\begin{tabular}{|c|c|c|c|c|c|c|}
\hline \multirow{2}{*}{ 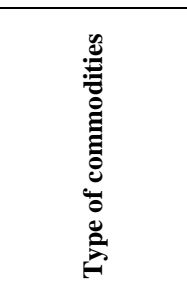 } & \multirow{2}{*}{ 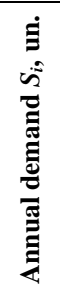 } & \multirow{2}{*}{ 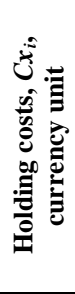 } & \multicolumn{2}{|c|}{ 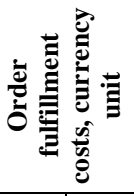 } & \multirow{2}{*}{ 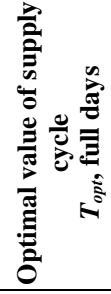 } & \multirow[t]{2}{*}{$q_{i}=T_{o p t} \frac{S_{i}}{D}$} \\
\hline & & & $C_{0}$ & $C_{i}$ & & \\
\hline Tea (10 sachets) & 700 & 1,0 & 50 & 2 & \multirow{3}{*}{90} & 173 \\
\hline $\begin{array}{l}\text { Whole bean } \\
\text { coffee }(1 \mathrm{~kg})\end{array}$ & 240 & 4,5 & 50 & 2 & & 59 \\
\hline $\begin{array}{l}\text { Sugar (800 } \\
\text { sticks) }\end{array}$ & 85 & 0,5 & 50 & 2 & & 21 \\
\hline
\end{tabular}
operating in HoReCa market of Zaporizhzhia.

Output data and calculation of "not perturbed" system parameters are given in Table I.

TABLE I. OUTPUT DATA AND CALCULATION RESULTS OF MULTI-NOMENCLATURE DELIVERY OF HORECA MARKET (ZAPORIZHZHIA)
«Perturbed» values of a multi-nomenclature delivery $T_{o p t}^{*}$, corresponding output data of Table I, as well as its relation with «not perturbed» parameter $\left(T^{*}{ }_{\text {opt }} /\right.$ ) for different values of $\varepsilon, n$ and $\beta=0,1$ $T_{\text {opt }}$

(parameter that characterizes holding cost increase) are

\begin{tabular}{|c|c|c|c|c|c|c|c|}
\hline \multicolumn{2}{|c|}{ 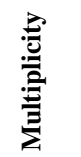 } & \multicolumn{2}{|c|}{$\varepsilon=0,01$} & \multicolumn{2}{|c|}{$\varepsilon=0,015$} & \multicolumn{2}{|c|}{$\varepsilon=0,02$} \\
\hline$n$ & $m$ & $T^{*}{ }^{*}{ }{ }^{\prime} / T_{o p t}$ & $T^{*}{ }_{o p}$ & $n$ & $m$ & $T^{*}{ }^{*}{ }{ }^{\prime} / T_{o_{I}}$ & $T_{t}^{*}{ }_{o p}$ \\
\hline 0 & 0 & 1,0000 & 90,00 & 1,0000 & 90,00 & 1,0000 & 90,00 \\
\hline 1 & 0 & 1,0045 & 90,40 & 1,0067 & $\begin{array}{l}90,60 \\
\end{array}$ & 1,0089 & 90,80 \\
\hline 2 & 0 & 1,0089 & 90,80 & 1,0134 & 91,21 & 1,0179 & 91,61 \\
\hline 3 & 0 & 1,0134 & 91,21 & 1,0202 & 91,82 & 1,0270 & 92,43 \\
\hline 4 & 0 & 1,0180 & $\begin{array}{l}91,62 \\
\end{array}$ & 1,0270 & 92,43 & 1,0361 & 93,25 \\
\hline 5 & 0 & 1,0225 & 92,03 & 1,0339 & 93,05 & 1,0454 & 94,09 \\
\hline 6 & 1 & 0,9795 & 88,16 & 0,9926 & 89,34 & 1,0059 & 90,53 \\
\hline 7 & 1 & 0,9839 & 88,55 & 0,9993 & 89,94 & 1,0149 & 91,34 \\
\hline 8 & 1 & 0,9883 & 88,95 & 1,0060 & 90,54 & 1,0241 & 92,17 \\
\hline 9 & 1 & 0,9927 & 89,34 & 1,0128 & 91,15 & 1,0333 & 93,00 \\
\hline 10 & 1 & 0,9972 & 89,75 & 1,0196 & 91,77 & 1,0426 & 93,84 \\
\hline 11 & 1 & 1,0017 & 90,15 & 1,0265 & $\begin{array}{l}92,39 \\
\end{array}$ & 1,0521 & 94,68 \\
\hline 12 & 2 & 0,9597 & 86,38 & 0,9857 & 88,72 & 1,0125 & 91,12 \\
\hline
\end{tabular}
presented in Tables II and III. There is comparative analysis of optimal cycle's values of multi-nomenclature delivery of HoReCa (Zaporizhzhia) when $m=\left[\frac{n}{6}\right]$ in Table II.

TABLE II. COMPARATIVE ANALYSIS OF OPTIMAL CYCLE`S VALUES OF MULTI-NOMENCLATURE DELIVERY,

$$
\mathrm{B}=0,1, m=\left[\frac{n}{6}\right] *
$$

Based on Table II data, it can be concluded that increased multiplicity of periods ( $\mathrm{n}$ and $\mathrm{m}$ ) of higher ordering and holding costs causes ordering period's fluctuations.

For example, gradual ramp up of order fulfillment costs' transport component by $1 \%(\varepsilon=0.01)$ during the first 5 periods and unchanged holding costs, entail the raise of order interval from 90 to 92 days. Even a one-time increase in holding costs $(n=6$ and $m=1)$ leads to decrease of the studied parameter from 92 to 88 days, or about $4 \%$. Further changes tend to recur.

Optimal periods of multi-nomenclature delivery of HoReCa segment in Zaporizhzhia when $m=\left[\frac{n}{3}\right]$ are calculated in Table III. 
TABLE III. CALCULATION OF OPTIMAL CYCLE`S VALUES OF MULTI-NOMENCLATURE DELIVERY OF HORECA (ZAPORIZHZHIA), $\mathrm{B}=0,1, m=\left[\frac{n}{3}\right]^{*}$

\begin{tabular}{|c|c|c|c|c|c|c|c|}
\hline \multicolumn{2}{|c|}{ 胥 } & \multicolumn{2}{|c|}{$\varepsilon=0,01$} & \multicolumn{2}{|c|}{$\varepsilon=0,015$} & \multicolumn{2}{|c|}{$\varepsilon=0,02$} \\
\hline \begin{tabular}{|l|}
$N$ \\
\end{tabular} & $m$ & $T^{*}{ }^{*}{ }^{\prime} t / T_{\text {opt }}$ & $T_{o p t}^{*}$ & $T^{*}{ }^{*}{ }^{2} t / T_{o p t}$ & $T^{*}{ }_{o p t}$ & $T^{*}{ }^{*}{ }^{\prime} t / T_{o p t}$ & $T^{*}{ }_{o p t}$ \\
\hline 0 & 0 & 1,0000 & 90,00 & 1,0000 & 90,00 & 1,0000 & 90,00 \\
\hline 1 & 0 & 1,0045 & 90,40 & 1,0067 & 90,60 & 1,0089 & 90,80 \\
\hline 2 & 0 & 1,0089 & $\begin{array}{l}90,80 \\
\end{array}$ & 1,0134 & 91,21 & 1,0179 & 91,61 \\
\hline 3 & 1 & 0,9665 & 86,99 & 0,9729 & 87,56 & 0,9794 & 88,14 \\
\hline 4 & 1 & 0,9708 & 87,37 & 0,9794 & 88,15 & 0,9881 & 88,93 \\
\hline 5 & 1 & 0,9752 & 87,76 & 0,9860 & 88,74 & 0,9969 & 89,73 \\
\hline 6 & 2 & 0,9344 & 84,10 & 0,9469 & 85,22 & 0,9595 & 86,35 \\
\hline 7 & 2 & 0,9386 & 84,47 & 0,9532 & 85,79 & 0,9680 & 87,12 \\
\hline 8 & 2 & 0,9428 & 84,85 & 0,9596 & 86,36 & 0,9767 & 87,91 \\
\hline 9 & 3 & 0,9037 & 81,33 & 0,9218 & 82,96 & 0,9403 & 84,62 \\
\hline 10 & 3 & 0,9077 & 81,69 & 0,9279 & 83,52 & 0,9487 & 85,38 \\
\hline 11 & 3 & 0,9117 & 82,06 & 0,9342 & 84,08 & 0,9572 & 86,15 \\
\hline 12 & 4 & 0,8744 & 78,69 & 0,8977 & 80,79 & 0,9218 & 82,96 \\
\hline
\end{tabular}

Calculations presented in Table III prove that growing multiplicity of ramping up ordering and holding costs ( $n$ and $m$ ) causes periods fluctuations of an optimal order. For example, with a threefold increase in holding costs $(m=3)$ when $\varepsilon=0,02, \beta=0,1$, and when $n=9$ the period of ordering shortens from 90 to 85 full days, or $6 \%$, which is quite significant. The following trend is repeated.

Let us analyze dependence of the order volume dynamics of one product category from HoReCa delivery (Zaporizhzhia), precisely tea (Figure 1).

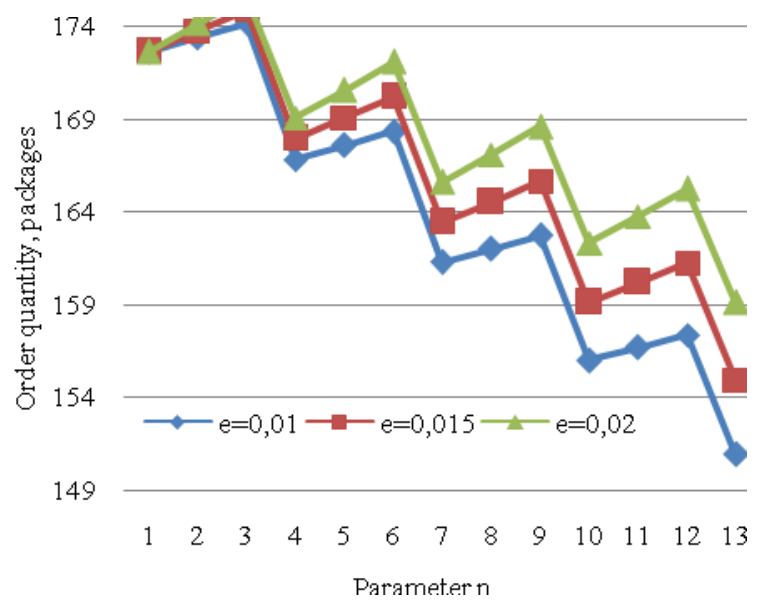

Fig. 1. Correlation of tea delivery`s order quantity change to parameters values $\varepsilon$ and $n^{*}$.
As a result of calculations we found out that increase of parameter $n$, which characterizes frequency of rising transportation costs to value 6 with a simultaneous rise of parameter $m$ (multiplicity of holding costs growth) to 2 leads to decrease in optimum order volume by 12 packages or almost $7 \%$ when $\varepsilon=0.01$; by 10 packages or $6 \%$ when $\varepsilon$ $=0,15$; by 7 packages or almost $4.1 \%$ when $\varepsilon=0.02$.

Figure 2 illustrates correlation of company`s total costs, operating in HoReCa segment in Zaporizhzhia from multiplicity of order and holding costs growth ( $n$ and $m=\left[\frac{n}{3}\right]$ ).

Holding costs growth causes a sinuous total costs surge. A twofold increase in holding costs entails total costs growth approximately by $13 \%$ when $n=6$.

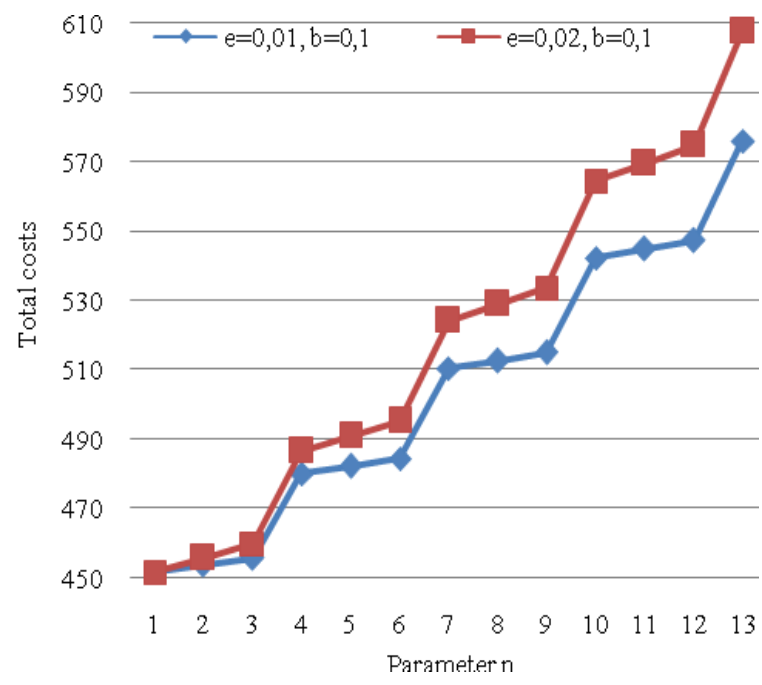

Fig. 2. Correlation of customer`s total costs` change to parameters values $\varepsilon$ and $\beta^{*}$

* Note: Authors`calculations

\section{CONCLUSIONS}

In this paper, we use asymptotic approach to modify the model for determining optimal order interval. It is based on perturbation methods that allow to solve problems, varying system parameters. This eliminates constraints imposed on the basic Wilson formula for fixing input parameters.

The asymptotic formula handy for companies management has been obtained for the situation when order fulfillment and holding costs cyclically increased. This formula allows to determine the optimum period between orders for multi- nomenclature delivery.

Multi-nomenclature model of optimization of inventory business processes was tested on the example of the enterprise operating in $\mathrm{HoReCa}$ segment of Zaporizhzhia regional market. The results indicate that increased multiplicity of ordering and holding costs growth leads to periods` fluctuation of an optimal order.

Thus, the developed multi-nomenclature inventory model will allow company`s management to optimize its business processes of order logistics, as well as apply 
situational management of these processes, modeling changes for businesses caused by holding and order fulfillment costs growth.

Prospects for further research are related to the application of asymptotic approach to inventory management models in case of system input variables. In particular, they can be used to model the situation associated with price change for resources which depends on order volume.

\section{REFERENCES}

[1] R. R. Larina, and O. Y. Luk'yanova, "Model of business processes in industry in direct development of logical management," Ekonomika ta derzhava, № 7, p.17-22, 2013. [in Ukrainian].

[2] G. V. Melnik, and V. I. Skitsko, "Modeling of logistic business processes using colored Petri nets," Current problems of the economy. No 6(168), p. 429-443, 2015. [in Ukrainian].

[3] A. A. Kolomitseva, and V. S. Yakovenko, "Modeling of processes of optimal management of logistic distribution systems," BUSINESS INFORM, No7, p. 18-21, 2012. [in Ukrainian].

[4] S. V. Ocheretenko, "On the issue of inventory management of automotive spare parts at commercial enterprises," Municipal economy of cities, No142, p. 114-118, 2018. [in Ukrainian].

[5] P. K. Tripathy, and S. Sukla, "Decision support model for perishable items impacting ramp type demand in a discounted retail supply chain environment," Yugoslav Journal of Operations Research, Number 3, p. $371-383,2018$.
[6] N. O. Markova, and I. A. Kiosєva, "Imitation to model management of stocks," Newsletter of the Berdyansk University of Management and Business, No2 (30), p. 50-56, 2015. [in Ukrainian]

[7] O. V. Posilkina, and Y. E. Novitska, Y. M. Punkin, O. Y. Gorbunova, "Victoria of the bagatomenomenclature of optimized models for the more precise management of stocks in the pharmaceutical industry," Management, economy and secure care in pharmaceuticals, No1(21), p. 56-62, 2012. [in Ukrainian].

[8] R. I. Yassa, and Z. F. Ikatrinasari, "Determination of multi-item inventory model with limitations of warehouse capacity and unit discount in leading garment industry in Indonesia," International Journal of Mechanical and Production Engineering Research and Development, Vol. 9, Issue 2, p. 161-170, 2019.

[9] C. K. Jaggi, and S. K. Goel, M. Mittal, "Credit Financing in Economic Ordering Policies for Defective Items with Allowable Shortages," Applied Mathematics and Computation, No 219 (10), p. 5268-5282, 2013.

[10] A. Eynan, and D. Kropp, "Effective and Simple EOQ-like Solutions for Stochastic Demand Periodic Review Systems," European Journal of Operational Research, No 180(3), p. 1135-1143, 2007.

[11] C. H. Wang, "Some Remarks on an Optimal Order Quantity and Reorder Point when Supply and Demand are Uncertain,"Computers and Industrial Engineering. No58(4). p. 809-813. 2010.

[12] A. Yousefli, M. Ghazanfari, "Stochastic Decision Support System for Economic Order Quantity Problem," Advances in Fuzzy Systems. URL: http://www.hindawi.com/journals/afs/2012/650419/.

[13] V. S. Lukinsky, Models and methods of the theory of logistics: textbook. St. Petersburg, Russia: SPb. 2007. [in Russian] 